\title{
Anticipation and Medically Assisted Life - giving - a Challenge to Reproductive Medicine
}

\author{
Mihai Nadin* \\ Institute for Research in Anticipatory Systems, University of Texas at Dallas, USA
}

Submission: July 17, 2017; Published: August 08, 2017

*Corresponding author: Mihai Nadin, Director, ante-Institute for Research in Anticipatory Systems, University of Texas at Dallas, USA, Email: nadin@utdallas.edu

\section{Introduction}

Reproductive medicine and the question of "Where Babies Come From" [1] are the appropriate context for trying out ideas-i.e., triggering a dialog about them - related to the creative nature of life. As everyone involved in reproductive medicine knows, the word "reproductive" itself is questionable. There is never a reproduction: each new life is unique; each new life is the outcome of an act of creation. Let's avoid any ambiguity: to create is to make possible something that never existed previously. But before we get to the creative nature of life, let's take note of a historic fact. As evinced down through the centuries of scientific inquiry, the brightest minds were able to explain how matter interacts, gravity, the movement of planets; they calculated celestial events and the weight of the Earth - but did not discover how babies were made, that is, how new life comes into being. "Sperm is a drop of brain" was an accepted view since antiquity; so was the view that sperm cells were parasites (an idea communicated by none other than van Leeuwenhoek, who examined his own sperm on the microscope he invented). Pregnant women and mothers of newborns do not menstruate, we learn from historic testimony, because mother's milk was made from menstrual blood. That until 1875 creation of life (from life) remained at best unclear conjures the realization that it was way easier to investigate the science of change in lifeless matter than in living matter. Still, in our days, comes a statement such as, "When analyzed in sufficient detail, everything is mechanical. The laws of physics are sovereign" [2].

The considerations to follow are not focused on particular aspects of reproductive medicine. But they offer a framework for understanding the making of life, inspiring science in general. The self-preservation of life ascertained as an axiom is best expressed in the object of medically assisted life-giving medicine (as I would rename reproductive medicine). The hope is that the broad framework articulated in the pages to follow could inform an anticipation-grounded practice of reproductive medicine, as opposed to reactive medicine. This would reflect the broader framework of anticipatory-based healing instead of repair inspired by a model of the human body as a machine in need of fixing [3].

\section{Anticipation and Change}

\section{Axiom 1: All there is, is the outcome of change}

The WHY? of change is straightforward: interactions. This pertains to all that there is: lifeless matter (the non-living) and the living embodied in matter. Interaction of a sexual nature is probably the most intuitive example. But asexual reproduction, in its many documented variations, is no less instructive of the same. The WHY? of interactions: matter and energy are interlocked in the identity of all that there is, as well as in all that will be (off spring). For an observer, the relative morphological stability (the form) of things is the immediate consequence of the intertwining of matter and energy ${ }^{1}$. Light as wave and particle - advanced and demonstrated within a quantum view - and for that matter the electron (particle and wave), are examples of the above description. But it also relates to the stable shape of a rock (what holds all the elements in place), water taking the form of a vessel, air filling a room. Birds of a feather, or sheep of a flock, or zebras of the same stripe, leaves and blades of grass are yet other examples - provided that the evolutionary process (variation and selection) is taken into consideration as well.

\section{Axiom 2: Self-preservation of life is the fundamental characteristic of the living embodied in matter}

The living, as a subset of all that there is, is self-preserving of its individuality and of its condition of being alive. Experimental evidence confirms the empirical basis of this pronouncement. A particular expression of matter and energy interlocked over a limited viability domain defines life: metabolism, self-repair,

${ }^{1}$ Physics developed the theory of forces to explain the same. 


\section{Global Journal of Reproductive Medicine}

and reproduction are aspects of life. Obviously, the life spans of a unicellular being or that of a tree or that of crustaceans are different; but nothing that comes to life can avoid the end of life. This thought is as significant as the dual nature of light or that of the electron. Outside the viability domain, the living becomes lifeless matter (while often hosting the life of other species); that is, its dynamics is reduced to that of the non-living. The viability domain is that of life making and creatively remaking itself (selfcreativity) through interactions - endogenous and exogenous. The interlocked matter and energy, in which the living is dynamically expressed, is the unity between sameness (birds of a feather, etc.) and difference. There are no two identical living entities. The living undergoes transformation processes - cell renewal - through which life is re-created. A woman's eggs (the largest cells in the body) and a man's sperm cells (a million times smaller) interact. Meiosis, a particular type of cell division, leads to a fertilized egg. There is no deterministic description that defines the WHY? of success, and even less the WHY? of each resulting living entity being an original.

The non-living manifests itself in its immediateness: the here-and-now of cause-and-effect interactions. The living, on account of self-preservation, extends from the immediate to the subsequent. Interactions characteristic of the living are several orders of magnitude more diverse, and of higher impact, than those defining the change of lifeless matter. Properties of lifeless matter are defined by the particles making up the matter and energy processes necessary to maintain them. This is a bottomup process - interactions (endogenous) among fermions, quarks, leptons, bosons, etc. to atoms and molecules, to physical entities, such as elements and things made from elements. Interactions with the world (exogenous) - some linear in nature, others nonlinear - affect their properties, as well, by influencing the matterenergy interlock. The description of their motion (trajectory, speed, continuity, etc.) is one possible way, chosen by physics, to characterize change (in relative position in the world, in this case).

\section{It's Time for Physics to Learn from Biology}

Properties of living matter result from complementary processes bottom-up and top-down. Feeling, emotion, and uncertainty affect the functioning of human "hardware," the matter making up brain, sensory organs, and heart. The anticipation expressed in sexuality is of the same nature as that in any other creative act. Energy - endlessly transformed but never created - is at work in affecting how matter supports life, or, outside the viability domain, undermines it. Descriptions of motion, relevant to physical entities (things in the immediate environment or entities at micro or macro scale, as in the domain of astrophysics) is of secondary significance. Ontogeny and phylogeny, as biological processes reflecting the dynamics of energy-matter interlocking, direct behavioral patterns, as much as they define material make-up, itself in continuous renewal. The unique genetic characteristics of each offspring are indicative of the process.

The never-ending change of any and all living entities from insemination to birth to death - entails creative processes. Reproduction (sexual or asexual), i.e., life giving, is, from among creative processes, the most prominent. To create is to make the past (what was, the genetics) and the present (what is) become a possible future (what might be), embodied in an original. For this, perception of the future, i.e., a "sense" of what might happen, informed by, but not reducible to, sensorial perception and the rich cognitive activity this triggers, is a condition sine qua non. This "sense" of the future is anticipation ${ }^{2}$ orchestrating biological expression (such as motoric expression) consonant with life selfpreservation. It is as though the stem cell, for example, "knows" all there is already in the world and becomes something that never existed before. The action, guided by anticipation - to which learning contributes meaning - transcends the actionreaction mode of lifeless matter - where meaning does not exist, and where repetition (same cause $\rightarrow$ same effect) is the law. In anticipatory action, what is - a blade of grass, an elephant, a woman, etc. - becomes something that never existed before in its concrete embodiment, even though it is recognizable as part of a species. Birth pangs (pre-partum contractions) are an example familiar to every woman who has given birth and every medical practitioner who has assisted in the process. They also realize that each outcome is unique. Therefore, anticipatory action can be qualified as creative. In contradistinction to change in lifeless matter, which is essentially deterministic and repetitive, anticipation-driven change is non-deterministic. It can be successful - creativity as self-preservation ("art of surviving") or not. Reproductive medicine is aware of this dynamics: more babies come to life because we are better in understanding the process.

a. Lemma 1: Anticipation processes underlie evolution. Self-preservation-guided variation and selection, from the cellular level to that of species, succeeds to the extent to which anticipatory processes lead to successful action. The WHY? of anticipation is straightforward: there is anticipatory action because there is change resulting from interactions of selfpreservation of life.

b. Lemma 2: There is anticipation because there is learning. A pregnant woman is a university in full session.

o The pregnant woman's body changes in anticipation of the pregnancy load.

o The physiology changes ahead of the many challenges related to the woman's body and the fetus's integrity.

${ }^{2}$ For an introduction to the science of anticipation, see Anticipation - The End Is Where We Start From (Nadin, 2003). This book and other articles on the nature and applications of anticipation can be found at www.nadin.ws and www.anteinstitute.org. 


\section{Global Journal of Reproductive Medicine}

o Processes never experienced before pregnancy are facilitated, e.g., contraction, sucking rhythm in advance of actual need.

o Lactogenesis is timed to the various phases of pregnancy (early, mid-term, pre-partum). Endogenous opioids inhibit some neuronal activity and thus facilitate prolactin activity.

o Maternal behavior: a term uses to describe how a mother's action (preparations of all kind, nursing, cleaning, etc.) is affected by hormonal priming of the medial preoptic area. Oxytocin, estrogen, progesterone, and prolactin are released in various areas of the brain, in particular the amygdala, which is associated with anticipatory activity.

Maternal behavior changes as pregnancy advances. For instance, activation of oxytocin release processes upon giving birth diminishes anxiety, although it can lead to aggressive behavior (for which medication is prescribed when self-control does not work).

Anticipatory action is facilitated by biophysical and biochemical processes not reducible to the physical and chemical processes characteristic of lifeless matter. Lifeless matter and living matter are made of elements - although molecules of life (proteins, carbohydrates, lipids, nucleic acids) are 96\% composed of six elements (carbon, hydrogen, oxygen, nitrogen, phosphorus, sulfur). But they are fundamentally different by the nature of interactions that each makes possible, moreover necessary, in order to ensure self-preservation of life. Anticipation has an existential condition (the WHY? of anticipation). Life selfpreservation is accomplished through anticipatory processes bridging the now with the possible future.

The understanding of anticipation conjures constructs such as time and space, within a systems' perspective: The current state of an anticipatory system depends on past, current, and possible future states. The dynamics of lifeless matter, i.e., its change, is fully described through the variables relating the past to the present (characterized as duration and proximity). The number and variety of parameters describing the non-living are finite (even though they can be very large). The dynamics of the living cannot be described and explained without considering the possible future. The number of variables describing the dynamics of the living is as open-ended as the possible futurebased choices it faces as it unfolds over its viability interval.

The interlocking of energy and matter in the living makes possible the simultaneous condition of sameness (in species, in offspring) and difference (expressed as individuality, of which lifeless matter has none). Interactions in lifeless matter and among non-living entities are described in the dynamics of action-reaction, i.e., deterministic causality (including, for instance, processes described in chaos theory). Inferences from parts to the whole are possible because interactions through which matter and energy are interlocked are preserved (up to a certain scale). Variations (an expression of our imperfect descriptions) appear to average out. Inferences from parts to the whole in the living are at best misleading. Interactions through which living matter and energy are interlocked is specific to each and every level life: cells, membranes, tissues, organisms, etc. Lifeless matter is homogenous: atoms, molecules, and aggregates are of the same nature. Life embodied in matter is heterogenous from the cell level to tissues, to organs, up to the organism. Homeostasis [4] - still preached to students of medicine - is nothing more than a generalization from an understanding of life as a machine. Allostasis [5] is probably a better description.

\section{Repetition without Repetition}

The non-living neither reproduces nor replicates itself. Life self-preserves itself through replication (of genetic elements such as DNA molecules) and reproduction. Intertwined sameness and difference correspond to creative change: life is always made from life, continued in never-repeated patterns. Medicine, dedicated to the self-preservation of life, uses technology in accomplishing this mission. In this respect, to be ignorant of science and technology would be irresponsible. To abdicate from its anticipatory condition would transform medicine, in particular reproductive medicine, into a technology in itself. Robotic medicine is already being advanced as a way to practice medicine. Sometimes the danger of this happening is dangerously downplayed. Too much is at stake when new life comes into existence that we can allow ourselves to be less than mindful of its meaning.

\section{References}

1. Dolnick E (2017) The Seeds of Life: From Aristotle to da Vinci, from Sharks' Teeth to Frogs' Pants, the Long and Strange Quest to Discover Where Babies Come From. Basic Books, New York, US.

2. Deutsch D (2011) The Beginning of Infinity: Explanations That Transform the World. New York: Viking.

3. Nadin M (2016) Medicine: The Decisive Test of Anticipation. In Anticipation and Medicine. Heidelberg/Berlin, Springer 1-27.

4. Cannon WB (1926) Physiological regulation of normal states: some tentative postulates concerning biological homeostatics. In A Charles Richet: ses amis, ses collègues, ses élèves. Petit A, Ed. Paris, Les Editions Medicales 91.

5. Shulkin J (2003) Rethinking Homeostasis: Allostatic Regulation in Physiology and Pathophysiology. Cambridge MA, MIT Press. 
Your next submission with Juniper Publishers will reach you the below assets

- Quality Editorial service

- Swift Peer Review

- Reprints availability

- E-prints Service

- Manuscript Podcast for convenient understanding

- Global attainment for your research

- Manuscript accessibility in different formats ( Pdf, E-pub, Full Text, Audio)

- Unceasing customer service

Track the below URL for one-step submission https://juniperpublishers.com/online-submission.php 